\title{
The prevention and cure research of emergency intervention therapy of balloon occlusion of LAD occurring reperfusion arrhythmia
}

\author{
Wang Z, Huang Z, Liu B, Yang X, Dong Q, Liu S, Zhang H, Sun C, Wang B and Li M \\ Vasculocardiology Deparment, North China Petroleum Administration General Hospital of Hebei Medical University, China
}

\begin{abstract}
Objective: Discussing whether occurs reperfusion malignant ventricular arrhythmia by intravenous injecting metoprolol before the intervention treatment of Left Anterior Descending (LAD) of Acute Myocardial Infarction (AMI) and observing the change of heart rate.

Method: Divided 85 AMI patients (From North China petroleum administration general hospital of Hebei medical university, July 2012-December 2016) randomly into 2 groups by admission time: 42 patients are in the prevent and treat group and the other 43 patients are in the non- prevent and treat group. Intravenous injecting metoprolol $16 \mathrm{mg}$ (within 3 minutes) into the prevent and treat group before the intervention treatment of (LAD), and recording two groups of patients arrhythmias which occurred after begin LAD (within 10 minutes). Finally, Statistical analyzing the condition of the malignant arrhythmia in all patients.

Result: Prevent and treatment group (42 patients): no ventricular arrhythmia: 38 patients (90.5\%); ventricular premature beat and antibiotics went: 2 patients (4.7\%); ventricular tachycardia: 1 patient (2.4\%). Non- Prevent and treatment group (43 patients):no ventricular arrhythmia:6 patients (14.0\%); ventricular premature beat and antibiotics went: 4 patients (9.3\%); ventricular tachycardia: 31 patients (72.1\%); ventricular fibrillation:2 patients (4.6\%). There has the significant difference between the prevent and treatment group and the non-prevent and treatment group in $\mathrm{RA}(\mathrm{P}<0.05)$.
\end{abstract}

Conclusion: Metoprolol can reduce the occurring of reperfusion malignant ventricular arrhythmia so that it reduces the death rate.

\section{Introduction}

The main cause for acute anterior myocardial infarction and extensive anterior myocardial infarction is LAD acute closure. The most effective and the preferred way of that is emergency percutaneous coronary intervention (PCI).

According to European Society of Cardiology (ESC) < Myocardial Revascularisation (with EACTS) $>$ [1], if the time of primary PCI related longer than $62 \mathrm{~min}$ will gain less from Systemic intravenous thrombolysis in terms of death rate [2], although recanalization of " culprit artery " could not only reduce the death rate by at least $25 \%$ but play a significant role on life quality improvement [3-5]. However, it will often happen reperfusion ventricular arrhythmias when carry on emergency PCI to open LAD. And the incidence of reperfusion ventricular arrhythmias by emergency PCI to open LAD is higher than (25\%) other acute coronary occlusion, even occur fatal ventricular tachycardia, ventricular fibrillation or sudden cardiac death [6-7]. And that increase the difficulty and risk of the treatment of left anterior descending branch intervenes. Therefore, in order to prevent the malignant arrhythmia and improve prognosis, we injection metoprolol ( $\beta$ blockers) before PCI to open LAD [8], and that have not seen in the literature of PCI preventing malignant ventricular arrhythmia. Therefore, the aim of our project is to observe the change of heart rate and to discuss whether the injection of metoprolol ( $\beta$ blockers) before PCI to open LAD could reduce malignant arrhythmia or could stop malignant arrhythmia.

\section{Materials and methods}

\section{General materials}

We picked up 85 AIM for emergency PCI treatment patients as the research of subjects from North China petroleum administration general hospital of Hebei medical university, July 2012-December 2016.

Inclusion Criteria:

1) Met the criteria for AMI [9].

2) Disease time less than 12 hours.

3) Eliminate old myocardial infarction and sub-acute myocardial infarction.

According to the admission time, we divided all the patients into 2 group (The prevent and treatment group and The non- prevent and treatment group). The prevent and treatment group includes 42 patients, 31 male patients and 11 female patients, ages are 32 to 83 .

Correspondence to: Zhongming Wang, Vasculocardiology Deparment, North China Petroleum Administration General Hospital of Hebei Medical University, China; E-mail: 1210149834@qq.com

Key words: anterior descending branch, acute occlusion, reperfusion, malignant arrhythmia

Received: October 22, 2017; Accepted: November 20, 2017; Published: November 24, 2017 
The non-prevent and treatment group includes 43 patients, 30 male patients and 13 female patients, ages are 34 to 84 .Patients in two groups had no statistical significance in gender, age, hypertension history, diabetes mellitus history and cardiac functional grading $(\mathrm{P}>0.05)$, having comparability.

\section{Methods}

Injecting metoprolol $16 \mathrm{mg}$ (within $3 \mathrm{~min}$ ) before PCI to open LAD to prevent and treatment group, and then carry on the LAD, including emergency percutaneous transluminal coronary angioplasty (PTCA) and PCI. While, direct carrying on LAD to non- prevent and treatment group, including PTCA and PCI. Recording the occurrence of arrhythmias (Ventricular premature beat, ventricular tachycardia and ventricular fibrillation).

\section{Statistical methods}

Statistical analysis was performed using SPSS19.0 statistical analysis software measurement data was described as mean \pm standard deviation $(\bar{x} \pm s)$, the comparison was presented by T- test between groups, enumeration data was measured by adopting $\mathrm{x} 2$ test. All data was tested with a $\mathrm{P}$ value of 0.05 indicating statistical significance.

\section{Results}

Preventive treatment group ( 42 cases) : 38 cases without ventricular rhythm (90.5\%), 2 cases with Premature Ventricular Beats(PVB) and bigeminy or trigeminy $(4.7 \%), 1$ case with ventricular tachycardia (2.4\%), 1 case with ventricular fibrillation (2.4\%).Blank Control group (43 cases) : 6 cases without ventricular rhythm(14.0\%), 4 cases with Premature Ventricular Beats(PVB)and bigeminy or trigeminy $(9.3 \%)$, 31 cases with ventricular tachycardia (72.1\%), 2 cases with ventricular fibrillation (4.6\%).Compared the arrhythmia situation after PCI treatment in 10 minutes between 2 groups, the statistical analysis results shown that $\mathrm{x} 2=49.829, \mathrm{P}<0.05$, the differences between two groups had statistical significance. Results were shown in Table 1.

\section{Discussion}

Reperfusion Arrhythmias (RA) is a complication in the reperfusion treatment of Acute Myocardial Infarction (AMI), while the successful reperfusion could lead to a fatal RA and open the Infraction Related Artery (IRA) as soon as possible is the key to the rescue of AMI [1011]. But emergency interventional therapy of opening Left Anterior Descending branch (LAD)'s IRA will cause the myocardial reperfusion injury and sympathetic budding constantly [12], which can result in ventricular arrhythmia, even generate ventricular tachycardia ventricular fibrillation, or a sudden cardiac death [13-16]. The mortality of this type of arrhythmia is 2.47 times of other complications caused by myocardial infarction [17].

Table 1. Comparison of the arrhythmia situation after PCI treatment in 10 minutes between 2 groups cases (\%)

\begin{tabular}{|c|c|c|c|c|c|}
\hline \multirow[b]{2}{*}{ Group } & \multirow[b]{2}{*}{ Cases } & \multirow{2}{*}{$\begin{array}{l}\text { No } \\
\text { ventricular } \\
\text { arrhythmia }\end{array}$} & \multicolumn{3}{|c|}{ Ventricular arrhythmia } \\
\hline & & & $\begin{array}{l}\text { PVB and } \\
\text { bigeminy or } \\
\text { trigeminy }\end{array}$ & $\begin{array}{l}\text { Ventricular } \\
\text { tachycardia }\end{array}$ & $\begin{array}{l}\text { Ventricular } \\
\text { fibrillation }\end{array}$ \\
\hline $\begin{array}{l}\text { Preventive } \\
\text { Treatment } \\
\text { Group }\end{array}$ & 42 & $38(90.5 \%)$ & $2(4.7 \%)$ & $1(2.4 \%)$ & $1(2.4 \%)$ \\
\hline $\begin{array}{l}\text { Blank } \\
\text { Control } \\
\text { Group }\end{array}$ & 43 & $6(14.0 \%)$ & $4(9.3 \%)$ & $31(72.1 \%)$ & $2(4.6 \%)$ \\
\hline $\mathrm{x} 2$ & \multicolumn{5}{|l|}{49.829} \\
\hline P Value & \multicolumn{5}{|l|}{$<0.05$} \\
\hline
\end{tabular}

Above all, opening the LAD's IRA will result in myocardial injury and arrhythmia induced by ischemia reperfusion, the preventive strategy is of great significance [18]. However, $\beta$ - receptor blockers can reduce the morbidity and mortality of this kind of arrhythmia [1920].The results show that Intravenous injection of $16 \mathrm{mg}$ metoprolol (within 3 minutes) before the interventional treatment of opening LAD can significantly reduce or completely avoid the malignant ventricular arrhythmias caused by reperfusion. It is definitely an effective prevention strategy. From Table 1, the incidence rate of no ventricular arrhythmia in preventive treatment group is obviously higher than the blank control group after PCI treatment in 10 minutes, while the incidence rate of Premature Ventricular Beats (PVB), bigeminy or trigeminy, ventricular tachycardia and ventricular fibrillation is clearly lower. The statistical data of curative effect after interaction is: $\mathrm{x} 2=$ 49.829, $\mathrm{P}<0.05$, it has significant statistical differences.

\section{Conclusion}

The deficiency of this research is that Scientifically, the data of arrhythmia situation should be recorded in 0-minute,3-minute,5minutes, 10-minute, but time is limited for the operation rescue of Acute Myocardial Infarction (AMI), which means it's hard to record all data in a timely manner and the integrity of this research might be affected. But it's extremely reliable that intravenous injection of metoprolol before the interventional treatment of opening LAD's IRA can reduce the incidence rate of the related-ventricular arrhythmia.

\section{References}

1. Task Force on Myocardial Revascularization of the European Society of Cardiology (ESC) and the European Association for Cardio-Thorscic Surgery (EACTS), European Association for Percutaneous Cardiovasular Interventions (EAPCI), Wijns W, Kolh P, Danchin N, et al. (2010) Guidelines on myocardial revascularization. Eur Heart J 30: 2501-2555. [Crossref]

2. Nallamothu BK $\square$ Bates ER (2003) Pereulaneous coronary intervention versus fibrinolytic therapy in acute myocardial infarction $\square$ is timing $\square$ almost) everything. Am J Cardiol 92: 824-826. [Crossref]

3. Antman EM $\square$ Anbe DT $\square$ Armstrong PW $\square$ Bates ER, Green LA, et al. (2004) ACC AHA guidelines for the management of patients with ST-elevation myocardial infarction executive summary. A report of the American College of Cardiology/ American Hcart Association Task Force on Practice Guidelines(Wriring Committee to revise the 1999 guidelines for the management of patients with acute myocardial infarction) $\square J$ Am Coll Cardiol 110: 588-636. [Crossref]

4. Schenkeveld L, Pedersen SS, van Nierop JW, Lenzen MJ, de Jaegere PP, et al (2010) Health-related Quality of life and long-term mortality in patients treated withpercutaneous coronary intervention. Am Heart J 159: 471-476. [Crossref]

5. Li R,Yan BP,Dong M, Yip GW, Chan CP, et al. (2012) Quality of life after percutaneous coronary intervention in the elderly with acute coronary syndrome. Int J Cardiol 155 : 90-96. [Crossref]

6. Mozaffarian D,Benjamin EJ,Go AS, Arnett DK, Blaha MJ, et al. (2015) Heart disease and stroke statistics-2015 update:a report from the American Heart Association. Circulation 131: e29-e322. [Crossref]

7. Valgimigli $\mathrm{M} \square$ Tricoci $\mathrm{P}$,Huang Z, Aylward PE, Armstrong PW, et al. (2014) Usefulness and safety of vorapaxar in patients with non-ST-segment elevation acute coronary syndrome undergoing percutaneous coronary intervention (from the TRACER Trrial). Am J Cardiol 114: 665-673. [PubMed]

8. Trigo J, Mimoso J, Gago P, Marques N, Faria R, et al. (2010) Female gender:an independent Factor in ST-elevation myocardial infarction. Rev Port Cardiol 29: 13831394. [Crossref]

9. Task Force on the management of ST-segment elevation acute myocardial infarction of the European Society of Cardiology (ESC), Steg PG, James SK. Atar D, Badano LP, et al. (2012) ESC Guidelies for the management of acute myocardial infarction in patients presenting with ST-segment elevation. Eur Heart J 3: 2569-2619. [Crossref]

10. Sánchez PL,Fernández-Avilés F (2011) Routine early coronary angioplasty after thrombolysis in acute ST-elevation myocardial infarction:lysis is not the final syep. Eur Heart J 32: 927-930. 
11. D’Souza SP, Mamas MA, Fraser DG, Fath-Ordoubadi F (2011) Routine early coronary angioplasty versus ischaemia-guided angioplasty after thrombolysis in acute STelevation myocardial infarction:a metaanalysis. Eur Heart J 32: 972-982. [Crossref]

12. Chen LS, Zhou S, Fishbein MC, Chen PS (2007) New perspectives on the role of autonomic nervous system in the genesis of arrhythmias. J Cardiovasc Electrophysiol 18: 123-127. [Crossref]

13. Shen MJ, Zipes DP (2014) Role of the autonomic nervous system in modulating cardiac arrhythmias. Circ Res 114: 1004-1021. [Crossref]

14. Liu T, Takimoto E, Dimaano VL, DeMazumder D, Kettlewell S, et al. (2014) Inhibiting mitochondrial $\mathrm{Na}^{+} / \mathrm{Ca}^{2+}$ exchange prevents sudden death in a guinea pig model Of heart failure. Circ Res 115: 44-45. [Crossref]

15. Ho JE, Bittner V, Demicco DA, Breazna A, Deedwania PC, et al. (2010) Usefulness of heart eate at Rest as a predictor of mortality,hospitalization for heart failure,myocardial infarction,and stoke in patients with stable coronary heart disease (Data from the Treating to New Targets [TNT] trial. Am J Cardiol 105: 905-911. [PubMed]

16. Mozaffarian D, Benjamin EJ, Go AS, Arnett DK, Blaha MJ, et al. (2015) Heart disease and stroke statistice 2015 update:a report from the American Heart Association. Circulation 131: e29-322. [Crossref]
17. Pedersen F, Butrymovich V, Kelbaek H, Wachtell K, Helqvist S, et al. (2014) Shortlong-term cause of death in patients treated with primary PCI for STEMI. $J$ Am Coll Cardiol 64: 22101-2108. [Crossref]

18. Priori SG, Blomstrom-Lundqvist C, Mazzanti A, et al. (2015) 2015 ESC Guidelines for the management of patients with ventricular arrhy-Thmias and the prevention of sudden cardiac death: The Task Force for the Management of Patients with Ventricular Arrhythmias and the Prevention of Sudden Cardiac Death of the European Society of Cardiology (ESC). Endorsed by: Association for European Paediatric and Congenital Cardiology (AEPC). Eur Heart J 36: 2793-2867. [Crossref]

19. Wright RS, Anderson JL, Adams CD, Bridges CR, Casey DE Jr, et al. (2011) 2011 ACCF/AHA focused Update incorporated into the ACC/AHA 2007 Guidelines for the M-Anagement of Patients with unstable angina/non-ST-elevation my-Ocardial infarction:a report of the American College of Cardiology Foundation/ American Heart Association task force on practice guidelines developed in collaboration with the American Academy of Family physicians,Society for Cardiovascular Angiography and In-Terventions,and the Society of Thoracic Surgeons. J Am Coll Cardiol 57: e215-367. [Crossref]

20. Hamm CW, Bassand JP, Agewall S, Bax J, Boersma E, et al. (2011) ESC Guidelines for the management of acute coronary syndromes in patients presenting with-out persistent ST-segment elevation:The Task Force for the management of acute coronary syndromes in patients presenting with-out persistent ST-segment elevation(ACS) in patients presenting with-out persistent ST-segment elevation of the European Society of Cardiology(ESC). Eur Heart J 32: 2999-3054. [Crossref]

Copyright: @2017 Wang Z. This is an open-access article distributed under the terms of the Creative Commons Attribution License, which permits unrestricted use, distribution, and reproduction in any medium, provided the original author and source are credited. 